\title{
Analysis of NBA Business Strategy
}

\author{
Yanbo Jin
}

\author{
Jiamusi No.1 High School, Jiamusi, Heilongjiang, China \\ Author's Email:1029039277@qq.com
}

\begin{abstract}
NBA is a huge sports league with a reasonable sum of business value. In order to run such a giant alliance, managers and components need to follow a complex managing system that will ultimately bring benefits to every part of the league. As a success, the business model of the NBA provides an example for other institutions to better manage enterprises and to gain profit.
\end{abstract}

Keywords: NBA, Business model, Cartel, Celebrity effect, Statistic

\section{INTRODUCTION}

NBA is a professional sports league which not only provides wonderful games to its audience but also contains impressive wisdom of managing a national, even international business alliance. To truly understand how this international business and sports league works, its historic background will be discussed and it decides how NBA generated. There are also complex managing systems that every member of it obeys involving in different administrators, trade and tax rules. Moreover, it advertises itself worldwide to attract billions of fans from a wide range of professions to gain profit. Also, it employs business tricks such as celebrity effect and industry monopoly to ensure its firm status in the sports industry and to bring profits to its investors. With every possible method it uses, it gradually develops from a tiny basketball club into an influential business alliance with about 750 million families watching it. As a wonderful success itself, NBA provides an authentic example that other enterprises can learn to increase their market value.

\section{HISTORICAL DEVELOPMENT}

The National Basketball Association (NBA) is one of the largest professional Basketball leagues in the world. It represents the highest level of Basketball. The predecessor of the NBA, the BAA, was founded in New York on June 6, 1946, and was merged into the NBA on August 3, 1949 by the NBL. At first, the NBA was a drug - and brawl-ridden league, discredited in the United States. In 1984, the market value of the NBA dropped to $\$ 15.5$ million and 17 of its 23 teams were on the verge of bankruptcy, the same year David Stern took over and ushered in a new era for the league. During his three decades at the helm, he gradually created the salary cap and other systems that kept the league afloat, turning it into the commercial behemoths it is now broadcast to 212 countries in 42 languages. Currently, there are 30 teams in the NBA.[1]

\section{COMPOSITION}

The highest administrative body in the NBA is the Office of the Commissioner. The office consists of ten departments, including administration, internal and external liaison, major events, finance, human resources, legal affairs, basketball operations, player training, security and team services. The internal and external liaison department and the large-scale events department also include six divisions and four divisions respectively.

A cartel is an alliance formed by an agreement on commodity price, output and sales among enterprises that produce or sell the same product to monopolize the market and obtain high profits. In the law of the United States, cartel is illegal. As a sports event, basketball has a very high demand for the competitive level. If multiple national leagues were dividing up the country's best players, each would presumably be less competitive and enjoyable to watch, attracting fewer viewers and making less profits. On the contrary, if a quality league monopolizes all the quality players and expands to maintain a high level of competition, the game will be much more enjoyable to watch. Thus, NBA is specially permitted by the US government to be a Cartel. Thanks to the permission, NBA has grown into a huge business league in the process of developing, expanding, and monopolizing[2]. 
Internally, as the highest authority of the alliance, the board of directors makes decisions on all matters within the alliance. The board of directors is held in November every year. If there are major issues to be solved, the board of directors can also hold a temporary meeting. The NBA Board of Directors has an employment relationship with the Commissioner and his management team. The Board of Directors has the right to make decisions and the Commissioner has the ultimate executive power. The NBA's board of directors is informed and approved by headquarters when it makes major decisions. When the president's proposal is approved by the board, the teams must implement it without conditions. The functions and jobs of the various NBA divisions are different, but the division of labor is clear, with each division head reporting to the Office of the Commissioner. The president goes directly to the department to solve major problems.

Externally, all teams in the NBA negotiate business as a group. Because the content of the game is protected by copyright law, broadcasters must pay the league for the rights to broadcast the game. By negotiating with the radio stations as a unified group, the league greatly reduces the chance for the radio stations to bargain, thus earning high broadcasting profits, which makes Cartel even more significant.

With the amount of revenue the NBA generates each year, it's natural that countless bosses who own their teams want to join the league. Nevertheless, the league's existing shareholders do not want anyone else to share their vast revenues, so a new team must be approved by three-quarters of existing shareholders and pay a hefty filing fee. For example, the Vancouver Grizzlies, now known as the Memphis Grizzlies, paid a \$32.5 million application fee when they joined.

\section{SOURCES OF INCOME}

\subsection{Admission Revenue}

During the regular season, home teams pay 6 percent of ticket sales to the league for each game (visiting teams get no benefit from ticket sales). In the playoffs, 45 percent of the ticket revenue from each game goes to the league. The league uses the money to distribute bonuses to teams that advance to the playoffs, as well as to reimburse officials and other officials for travel expenses and grants.

\subsection{Right to Broadcast Television}

Television revenue is also the NBA's main source of revenue, and the NBA provides NBA consulting services to thousands of media outlets around the world every day. In addition, during the NBA games, they also issue interview certificates to all countries in the world. NBA makes full use of the role of television media to promote it vigorously and get a huge amount of television rebroadcast fees. From 1997 to 1998 season, NBA had cooperative relations with 109 television stations around the world, and broadcast NBA games in 195 countries and 41 different languages. NBA games were watched by more than 600 million households, and the annual television rebroadcasting fee was $\$ 275.5$ billion. Big broadcast platforms, such as TNT and ESPN, also make important contributions to the promotion of the NBA. At the same time, NBA also provides all kinds of NBA programs to TV stations. Globalization promotion has expanded the NBA market to the whole world. The NBA recently signed a six-year, $\$ 4.6$ billion television deal with three television networks. Television paid $\$ 800,000$ a minute for a spot in the NBA Finals during the 19961997 season.

\subsection{Advertising Revenue}

The NBA equally shares the money in business contracts with all the teams. To keep pace with the international development, the NBA is expanding its market into peripheral products, including the production of some star memorabilia, the NBA store merchandise sales, jersey sales and other aspects of the operation are very detailed. Teams also get their own AD revenue. For example, the Golden State Warriors signed a three-year, $\$ 60$ million jersey AD deal with the Lotte Group. Stern also established NBA cable TV, NBA website and other entertainment programs, which have become almost a fixed mode of operation for the basketball league, making the NBA's advertising revenue grow day by day. At present, the Alliance's clothing includes Adidas and Nike, drinks include Coca Cola and Gatorade, food includes McDonald's, the Internet includes AOL, and even children's toys are sponsored by LEGO.

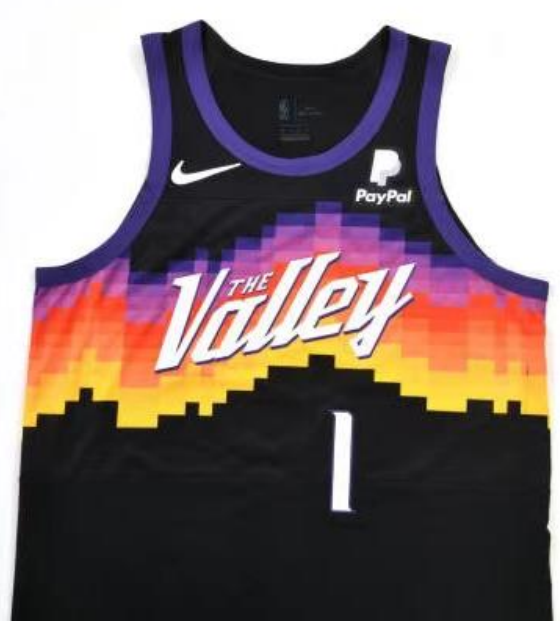

Figure 1 logo of the brand on jersey[3] 


\section{ADVERTISEMENT}

\subsection{Overseas Events: All-Star Weekend}

The NBA's Summer League and preseason games allow non-NBA teams to play, and some of the more popular teams are assigned to play preseason games overseas. In 2004, Yao's Rockets and Kings played one game each in Shanghai and one in Beijing. In 2007, the Cavaliers, led by James, played in Shanghai against the Magic, led by the prime Dwight Howard. As recently as 2019, the Lakers with LeBron and Anthony and Kyrie 's new team, the Nets, also showed up in the preseason in China. Clearly, overseas tournaments featuring teams with famous stars play a key role in increasing media exposure and attracting new audiences.

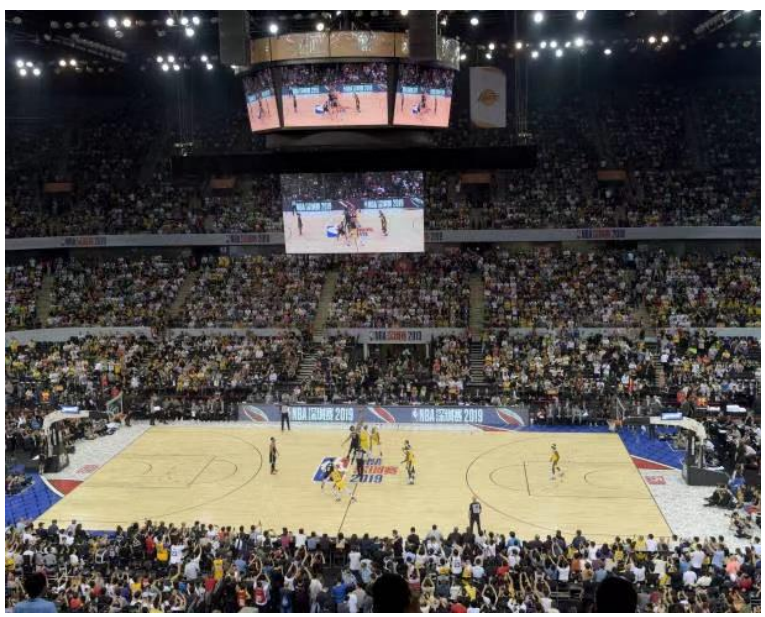

Figure 2 NBA China Game 2019 [4]

On March 2, 1951, the first All-Star Game was played at Boston's TD Garden. Tens of thousands of fans came to watch the game and the response was good. Since then, the dunk contest, the 3-point contest, the skill contest and the rookie contest were added to the All-Star Weekend and made the entertainment more appealing to audiences. The All-Star Game does not focus on the result of the game, it means to provide audiences a spectacular basketball show performed by all the more popular players voted by fans and media, which is an entertainment for the players to relax and better prepare for the next stage of the Season. "UFO" Carter's reverse windmill in 2000; Lavine and Gordon's incredible dunk contest in 2016 has been cherished in the hearts of countless fans. Especially in 2019, the farewell to Dwyane Wade, the Flash, and Dirk Nowitzki, the German Chariot have signed the ending of a generation' s youth, and fans in the gym cried to say goodbye to them. In 2020, in memory of the loss of great Kobe Bryant, the game adjusted its rule a little and make the final quarter play the intensity of the finals level. Therefore, the relaxed and happy atmosphere of the All-Star Weekend attracts a large number of fans to watch and plays a significant role in the promotion of NBA

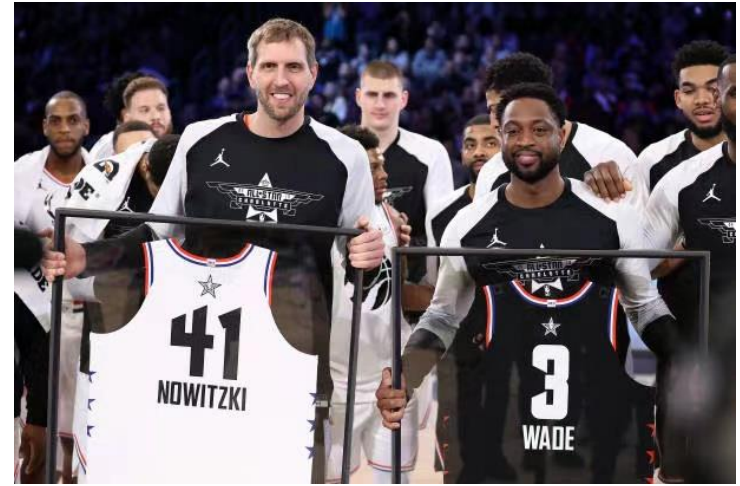

Figure 32019 NBA All-Star[5]

\subsection{Star Power}

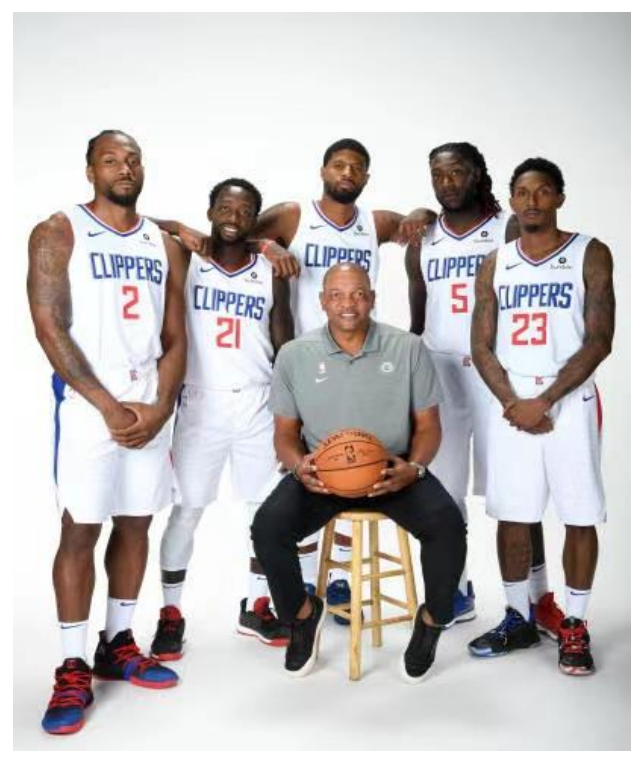

Figure 4 Los Angeles Clippers [6]

Celebrities have crucial effects on people' $\mathrm{s}$ behavior. For instance, before Kawhi Leonard and Paul George joined the Los Angeles Clippers, there were few journalists in the Media Room. Now, with the two superstars in the team, Clippers' Media room is crowded with reporters. Another example here is that LeBron James, the most influential player in NBA, ate Red Vines, a brand of candy in front of the cameras, enabling the company to earn $\$ 2.6$ million in one single day. Famous players have become so important for the league to make money. 


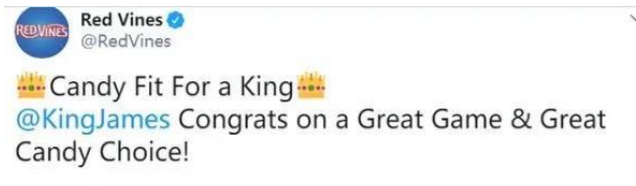

\#RedVines \#PeaceLoveandVines \#Candy \#Lebron

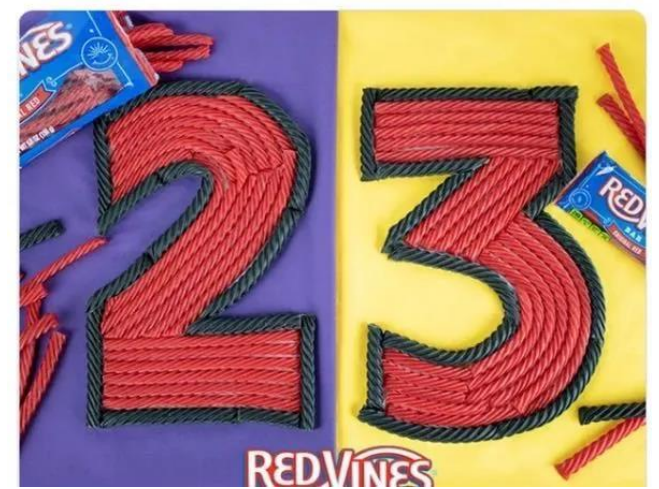

Figure 5 Red Vines responded to LeBron James[7]

\section{CONCLUSION}

All the businesses raise from nothing. As eminent as NBA, it started from a tiny sports club that almost had no audience group. Managing a variety of business skills, NBA gradually built up its base. It first advertised itself widely to make it known to more people. Then, to make it more watchable, it invited games with more than one simple rule. When reputed players appeared in the league, NBA relies on them to further advertise itself and attract more watchers. As NBA growing larger and larger, it takes advantage of its reputation to earn itself some special rights to monopolize in the nation Having set a firm position in the domestic market. It started to explore the international market and brought its games overseas. Step by step, NBA evolves into a domesticate basketball league which no other organization can compete with it. The phenomenal business tricks involved in its development are worth investigating throughout by other enterprises which also want to be outstanding in the industry. Due to the limited knowledge of the author, this article focus on only a few aspects of the business model of the NBA. It may be completed with a more wellrounded analysis.

\section{ACKNOWLEDGMENT}

Thanks to my teacher' $\mathrm{s}$ patient and professional guides. This essay cannot be completed without their support and help. Thanks to Professor Renzoni, he taught me how to deal with complex data and methods to solve problems. Thanks to Assistant Professor Qi who enthusiastically answers all my questions on and off classes.

\section{REFERENCES}

[1] Wu Yulong. Analysis of NBA Operation Mode. Sports Culture Guide 000.004 (2015): 155-158.

[2] Xi Yubao. American Professional Sports League and Cartel Industry Monopoly[J]. Journal of Beijing Sport University, 2004(04):34-35+45.

[3] https://www.gettyimages.nl/detail/nieuwsfoto's/thephoenix-suns-unveil-the-new-nike-city-editionjerseys-nieuwsfotos/1229879700

[4] https://www.gettyimages.nl/detail/nieuwsfoto's/jarr ett-allen-of-the-brooklyn-nets-battles-for-the-jumpnieuwsfotos/1175386830

[5] https://www.gettyimages.nl/detail/nieuwsfoto's/dirk -nowitzki-of-team-giannis-and-dwyane-wade-ofteam-nieuwsfotos/1130610647

[6] https://www.gettyimages.nl/detail/nieuwsfoto's/kaw hi-leonard-patrick-beverley-paul-george-headcoach-doc-nieuwsfotos/1173434260

[7] https://www.instagram.com/p/B9CRwCgF55X/?igs hid=11ovogoeqi $7 \mathrm{db}$ 